\title{
Preschool Children's Understanding of the Graphic Features of Writing
}

\author{
Jennifer Mortensen* \\ University of Arizona
}

\author{
Melissa Burnham \\ University of Nevada, Reno
}

\begin{abstract}
This project examined 2, 3, and 4-year-old children $(N=34)$ in a university campus child care setting to assess their understanding of the graphic features they use in their emergent writing (to distinguish it from a drawing of the same referent). The graphic features present in samples of the children's work were examined and compared to the graphic features children could identify through verbal and nonverbal communication. We examined the frequencies of graphic feature identification, as well as significant differences between graphic feature usage and graphic feature identification. The most frequently used graphic features were linearity, unidirectionality, and small size of units. The most frequently identified graphic feature was conventional letter. Overall, children used significantly more graphic features than they were able to identify. Significant relationships comparing the 2-year-old group and 4-year-old group's usage and identification were also found. The findings are discussed in terms of their application to early childhood classrooms. Teachers can apply these findings when engaging children in conversations about their emergent writing; these discussions are explored as a beneficial teaching tool.
\end{abstract}

Keywords : early childhood education, emergent writing

The written word is an integral part of industrialized society, thus writing is incorporated heavily in school classrooms. Within the context of early childhood education, emergent writing is an important piece of children's overall literacy development and future literacy skills (Whitehurst \& Lonigan, 1998). An important step for emergent writers is familiarization with the graphic characteristics that govern the writing script of their culture. Each writing script is governed by the rules of a corresponding orthography. The orthography of a written language dictates how marks must

* Corresponding Author: Jennifer Mortensen, Family Studies and Human Development, University of Arizona, 650 N. Park Ave. Tucson, AZ 85721, USA. E-mail: jenmort@email.arizona.edu "look" in order for meaningful interpretation to take place (Gibson \& Levin, 1975). The very beginnings of writing and other forms of notation, such as drawing, begin with indistinguishable marks on paper. By age 3, children consistently make the deliberate effort to graphically organize their marks in such as way that reflects their understanding of writing as a specific context (Harste, Woodward, \& Burke, 1984). Graphic features can be considered as "features of form which distinguish a written display from a drawing of the same referent” (Tolchinsky-Landsmann \& Levin, 1985, p. 320). The graphic features children use in writing have been the subject of a large body of research (Brenneman, Massey, Machado, \& Gelman, 1996; Clay, 1975; 
Ferreiro \& Teberosky, 1982; Gibson \& Levin, 1975; Gombert \& Fayol, 1992; Hildreth, 1936; Harste et al., 1984; Levin \& Bus, 2003; Sulzby, Barnhart, \& Heishima, 1989; TolchinskyLandsmann \& Levin, 1985; Treiman \& Yin, 2011). Researchers also have examined what children know about the graphic differences between writing and drawing through sorting and classification tasks (Akita, Padakannaya, Prathibha, Panah, \& Rao, 2007; Gombert \& Fayol, 1992; Lavine, 1977; Levin \& Bus, 2003; Tolchinsky-Landsmann \& Karmiloff-Smith, 1992; Tolchinsky-Landsmann \& Levin, 1985).

While these studies offer a great amount of information, little is known about children's understanding of the graphic features they use in their own writing, in terms of what they can express through conversation. The purpose of this study was to explore what children (ages 2, 3 and 4) have to say about features they use in their writing to make it look different from their drawing. Specifically, this study examined a group of children enrolled in a child care center on a university campus. We investigated which graphic features children could verbally identify when comparing examples of their own writing and drawing. Examining children's understanding of the graphic differences between drawing and writing provides early childhood educators with deeper knowledge of how children perceive their own emergent writing, and emphasizes the importance of facilitating conversations about writing in the classroom.

\section{Sociocultural Influence of the Classroom}

The rationale for this project is rooted in Vygotsky's (1978) sociocultural theory. From this perspective, the social world of the preschool classroom is a constant influence on children's development. The experiences that take place in the classroom context are widely recognized as important influences on children's development (National Institute of Child Health and Human Development [NICHD], 1998) and it is estimated that of U.S. families with employed mothers, over 11 million children experienced some form of child care arrangement, with 35\% experiencing centerbased (i.e., classroom) care (U.S. Census Bureau, 2005). Sociocultural theory also emphasizes the internalization of cultural skills, such as writing, as a major influence on children's development. Additionally, sociocultural theory emphasizes the collective, social influences that help drive development, such as teacher-student interactions and conversation. Based on Vygotsky's theory, Dyson (2008) frames the development of writing within the classroom as something that is much more complex than learning conventional rules and marks; it is rooted in the cultural and ideological practices of society. Preschool children have opportunities to practice writing and discuss features of writing with teachers, as well as opportunities to learn from peers. In the U.S., print is heavily incorporated into the early childhood classroom environment and curriculum (Love et al., 2007), exposing children to the features of their language's orthography long before they have the ability to read and print conventionally. The classroom context provides ample and meaningful opportunities to engage children in conversations about writing. Within the classroom context, this study examines what children understand about their own emergent writing, in terms of what they can express through conversation.

\section{The Differentiation of Drawing and Writing}

Differentiation is the process of distinguishing between drawing and writing, both mentally and graphically. Historically, Vygotsky (1978) and Luria (1929) shared the view that drawing and writing originate from the same place within the individual; drawing emerges first, then writing evolves from it. Early literacy researchers, such as Clay (1975), brought forth the idea that children understand a great deal about writing as a system and a context (different than drawing) before they are able to execute conventional writing. 


\section{Earliest Writing}

Children's earliest writing productions are commonly referred to as "scribbles," which often (mistakenly) implies a sense of random mark-making (Harste et al., 1984). Children may use what appear to be similar nonrepresentational marks for both drawing and writing until approximately age 4 (Tolchinsky, 2003); however, these marks, while not always visually distinguishable, differ in their meaning and intention (Clay, 1975). The process that children engage in to create these "scribbles" often reflects real knowledge of writing and literacy. Harste et al.'s (1984) observations document the intentionality behind children's writing, even when it is visually indistinguishable from their drawing. For example, children were asked to write their name and draw a picture of themselves; the end products looked very similar, but when the process children engaged in to create each production was analyzed, it became evident that children place considerable meaning on the "scribbles" they use to write with. Adi-Japha, Levin, and Solomon (1998) also documented children as young as 2 attributing different meanings to the different types of "scribbles" they create (e.g., curves, lines, circles, etc.).

\section{Writing and Drawing as Notational Systems and Domains of Knowledge}

Children's understanding of the differentiation between writing and drawing is best understood when writing and drawing are viewed as separate notational systems. According to Tolchinsky-Landsmann and Karmiloff-Smith (1992), two types of understanding are acquired for each notational system: (1) understanding of the notational system as a communicative tool (e.g., a child writes a letter to a friend) and (2) understanding of the notational system as a domain of knowledge (e.g., unique marks, action plans, rules). Understanding writing as a domain of knowledge has been documented in children as young as 2 (Treiman \& Yin, 2011; Yamagata,
2007). Children understand each notational system as its own domain long before they are able to produce conventional examples of drawing and writing. For example, when asked to write, young children will use linear and directional marks, while discussing the length of words and letters; however, when asked to draw, children will create boundaries, filled in areas, and choose to use colored markers, all while discussing the physical characteristics of the object (Brenneman et al., 1996). Yamagata (2007) and Treiman and Yin (2011) observed children as young as 2 producing marks recognizable to adults as writing (as compared to their drawing). Tolchinsky-Landsmann and Karmiloff-Smith (1992) devised a series of sorting tasks to determine which graphic constraints children impose on writing. The majority of children, ages 5 and 6, applied very specific constraints when determining which examples were "good for writing" versus "not good for writing." These children were even able to violate these constraints when researchers asked them to make up nonsense words, demonstrating children's implicit understanding of the differentiation of drawing and writing.

Many research studies have observed an interesting phenomenon that lends support to the theory that children understand writing as a domain of knowledge: children often refuse to write upon request by an adult (Brenneman et al., 1996; Yamagata, 2007). Children also consistently select conventional writing as superior to their own writing (Gombert \& Fayol, 1992). These results indicate that children recognize their inability to produce writing properly; children are demonstrating understanding of writing as a domain of knowledge when they acknowledge writing as a system with specific rules and marks.

In sum, the differentiation of writing from drawing is occurring in children's work long before they are able to represent it with conventional examples. Children attribute meaning to their earliest writing productions and have a beginning understanding of how writing differs from drawings. Children understand that 
writing is a system that has unique rules, is comprised of certain marks, and has accompanying action plans and vocabulary. One way to assess children's understanding of writing is to conceptualize writing and drawing as distinct notational systems and domains of knowledge. The current study examined children's knowledge about emergent writing from the perspective that even very young children engage in intentional writing and use their knowledge about writing as a distinct notational system and domain to graphically differentiate their writing from drawing. Our aim was to examine children's understanding of the graphical differences between their drawings and writing, in terms of what they can express in conversation, a technique that has not been previously used.

\section{The Graphic Features of Writing}

When children observe print in the outside world, they are sensitive to the graphic features of writing. Graphic features of all orthographies can be classified as either superordinate or ordinate (Gibson \& Levin, 1975). Superordinate graphic features include overarching characteristics of all orthographies, such as linearity, distinct units, regular blanks, and unidirectionality; ordinate features of writing are orthography-specific and include features such as the specific type of linearity (horizontal or vertical), direction (left-to-right, right-to-left, top-to-bottom), and specific shape of symbols (alphabet) (Tolchinsky, 2003). Children at very young ages can distinguish between writing and drawing because they are sensitive to superordinate and ordinate graphic features of writing (Ferreiro \& Teberosky, 1982; Lavine, 1977; Pick, Unze, Brownell, Drozdal, \& Hopmann, 1978; Tolchinsky-Landsmann \& Karmiloff-Smith, 1992; Treiman, Cohen, Mulqueeny, Kessler, \& Schechtman, 2007; Yamagata, 2007). The methodology of research on this topic is similar across studies, assessing children's knowledge through classification and sorting tasks.

\section{Children's Understanding of the Graphic Features}

Children show a preference for writing examples that demonstrate horizontal linearity (when horizontal linearity is the orientation of the orthography) (Lavine, 1977). Similarly, English-speaking children, ages 3 and 4, are more likely to state that their name is written properly if letters are along a horizontal line rather than a vertical or diagonal line (Treiman et al., 2007). By age 5, children believe that writing should be made up of multiple units that vary in shape. Ninety-two percent of 5 to 6 year olds classify a single letter (e.g., P) as not good for writing (Tolchinsky-Landsmann \& Karmiloff-Smith, 1992). Over 50\% of children age 4 , and $75 \%$ of children age 5 classify strings of repeated letters (e.g., TTTTT) as poor examples of writing. Young children have a large range of practical knowledge concerning the graphic features of writing; they are able to easily visually differentiate writing from drawing, and decide what constitutes writing based on numerous characteristics including linearity, variety and number of marks, types of symbols or letters.

\section{Children's Use of Graphic Features}

As discussed earlier, children are engaged in meaningful writing before their writing productions look conventional (Adi-Japha et al., 1998; Clay, 1975; Harste et al., 1984). Over time, children begin to incorporate their understanding of the graphic features in to their own writing productions. Children as young as 2 produce marks that are recognizable to adults as writing (Treiman \& Yin, 2011; Yamagata, 2007). Children generally show consistent use of graphic features by age 4 (TolchinskyLandsmann \& Levin, 1985), to the point that adults can consistently recognize the productions as writing (Levin \& Bus, 2003). As expected, children's use of graphic features generally increases with age (Akita et al., 2007; Levin \& Bus, 2003). 
Overarching superordinate features found in all orthographies generally appear in children's writings before orthography-specific ordinate features. Writing marks become linear early in the process. Between the ages 3 and 4, Tolchinsky-Landsmann and Levin (1985) reported a great increase in the use of linearity. Brenneman et al. (1996) reported that at ages 4 to $5,70 \%$ of written words displayed linearity, and at ages 5 to 6 this number jumped to $96 \%$.Children as young as age 3 , begin to use unidirectionality in their writing, but confuse the specific type of directionality (e.g., right-to-left versus left-to-right) until about age 5 (Tolchinsky-Landsmann \& Levin, 1985). Segmentation and small size of marks (as compared to marks made for drawing) are also common at age 4 (Ferreiro \& Teberosky, 1982; Tolchinsky-Landsmann \& Levin, 1985). Features such as wavy lines, circles, and pseudo-letters (letter-like approximations) are also commonly observed in children's emergent writing. Children use circles and pseudo letters in their writing before the use of conventional letters; however, there is some overlap, with a shift to conventional letter use occurring between 4 and 6 (Gombert \& Fayol, 1992; Levin \& Bus, 2003; Levin \& Korat, 1993; Sulzby et al., 1988; TolchinskyLandsmann \& Levin, 1985). Children's understanding of these graphic features was the main focus of this study. Based on this literature, certain graphic features of writing were selected as the focus for this project: linearity, unidirectionality, segmentation, small size of units, pseudo-letter, conventional letter, and the refusal to write response.

\section{Conversations About Writing}

Research consistently demonstrates that, when given the opportunity, children have a lot to say about their writing. For example, according to the conversations published in Ferreiro and Teberosky's (1982) classic research, children can communicate when they are writing or drawing and show the understanding that writing "says" something, whereas drawing "is" something. For example, one 4-year-old girl drew a picture and called it a "little toy." The interviewer asked, "It says little toy or it is a little toy?" The girl replied, "It is a little toy." The interviewer stated, "Write so it says little toy." The girl added wavy linear lines under the picture (Ferreiro \& Teberosky, 1982, p. 186). Conversations also allow children to express their intentions as well as their knowledge about writing as a notational system. For example, Treiman et al. (2007) presented children with conventional and unconventional printed versions of their name and asked them to select which versions displayed how their "name should look" (p. 1464).

When unconventional "ab" and “aB" capitalization patterns (e.g., michael, mICHAEL) were displayed, children discussed the shape and size of the letters as reasons for rejecting the versions. When children's names were presented with unconventional linear orientation (e.g., diagonal), children provided verbal explanations concerning the orientation (e.g., "It's a staircase”). Research such as this demonstrates that children have thoughts concerning their writing and drawing and are able to express them through conversation. While it is not absolute that children's understanding is exactly in line with their verbal abilities, from a sociocultural perspective, these social interactions are a key component and window to children's development (Vygotsky, 1978).

In sum, the purpose of this study was to examine children's (ages 2, 3, and 4) understanding of the graphic features they use in their own emergent writing, in terms of what they can express in conversation. Specifically, we were interested in examining: the frequency of graphic feature identification, possible differences in the number of graphic features identified compared to the number of graphic features actually used, and possible age differences in graphic feature identification and use. 


\section{Method}

\section{Participants}

The sample for this project was comprised of children attending a nationally accredited child care center on a university campus. All families of typically developing children between the ages of 2 and 4 were invited to participate. The original sample consisted of 39 children from families who consented to participate. Three children were selected to be pilot participants. Despite family consent, two children refused to assent to participate in the data collection meeting, eliminating them from the study. Of the remaining 34 children (21 female, 13 male), there were 8 2-year-olds, 14 3-year-olds, and 12 4-year-olds. The mean age of the children was 3.12 years $(S D=0.77)$. Of the 34 participants, 32 families returned complete family information and background forms to assess family demographic characteristics. Seventynine percent of the families were currently married, and $82 \%$ percent of them were Caucasian. Ninety-six percent of children had families with college degrees or higher, and $72 \%$ lived in households with an income of $\$ 75,000$ per year or more. The mothers' mean current age was $36.84(S D=6.47)$ and the fathers' mean current age was $37.19(S D=6.10)$. Six participants (17\%) spoke a language other than English at home; however, English was primarily used within the child care center, and all six children were proficient in English. At the child care center, the children were exposed to books and other forms of print, as well as a variety of writing materials. Writing was not formally taught in these classrooms, but was encouraged and supported through an emergent curriculum. The English orthography was the primary orthography children were exposed to in these classrooms, and thus the only orthography used in this study.

\section{Procedures}

Approval for this project was obtained from the Office of Human Research Protection and the Child and Family Research Center Research Committee at the University of Nevada, Reno. Upon consent, the parent or legal guardian of the child was asked to complete a self-administered questionnaire concerning basic demographic information. Items included, child's age (in years), child's gender, age of mother, age of father, sibling information, marital status, racial/ethnic background, level of education, and household income.

Each child participated in a structured, videotaped activity and interview in a room next to their classroom. Participants were presented with blank 5x8 inch index cards and black pens; they were then asked to draw then write two referents: (1) house and (2) flower. These referents were selected because they are generic, common shapes children often draw. Drawing the referent before writing provided participants with a comparison; with the drawing and writing examples next to each other, the participants could examine any differences between their two productions (adapted from TolchinskyLandsmann \& Levin, 1985). After a participant completed a drawing and writing example of the first referent, the interviewer asked the participant to examine the two productions and explain the differences between the marks used in the writing example versus the drawing example. An interview script contained questions such as, "Do these look different to you? How are they different?", "When you made these marks with your pen, what did you do to make them look like a picture?" and, "When you made these marks with your pen, what did you do to make them look like a word?” It was expected that some children would refuse to write (Brenneman et al., 1996; Sulzby et al., 1988; Tolchinsky-Landsmann \& Levin, 1985). The interview script included multiple prompts such as, "Please try to write [referent] the best way you know how," and, "If you were pretending to write [referent] what marks would you make?” After the interview for the first referent was complete, the same procedure was repeated for the second referent. The activity and interview yielded two groups of graphic feature data for each child: (1) graphic 
features used (GF-used) and (2) graphic features verbally identified (GF-id).

\section{Operationalization of Graphic Features}

Based on the literature, certain graphic features were selected as the focus for this study (Gibson \& Levin, 1975; Gombert \& Fayol, 1992; Levin \& Bus, 2003; Sulzby et al., 1989; Tolchinsky-Landsmann \& Levin, 1985): linearity unidirectionality, segmentation, small size of units, pseudo-letters, conventional letters, and the refusal to write response. Each feature was operationalized for the purpose of this study.

Linearity. Linearity was considered used if a single, straight line could be drawn through at least half of the marks, so that each mark was touching the line at some point. The marks did not have to be created in direct succession, but the end product had to demonstrate linearity. Linearity was considered identified by children if they stated that the marks were in a line, linedup, were along a line, or were next to each other. Linearity was also considered identified if children traced a line(s) with their finger either in the air or across the paper (e.g., the child states, "It goes like this," and moved finger in a line). If the line(s) children traced moved in various directions, only linearity was present.

Unidirectionality. During the interview, after each writing sample was completed, the interviewer indicated the directionality of the marks by drawing an arrow in the direction the child moved his or her hand to create the marks (adapted from Tolchinsky-Landsmann \& Levin, 1985). Unidirectionality was considered used if the arrow indicated movement in a single direction (for at least half of the marks), meaning that the marks were made in direct succession of one another. Because of the young age of the participants, unidirectional movement was not restricted to the English orthographic ordinate feature of left-to-right directionality (Gibson \& Levin, 1975). Unidirectionality was considered identified by children if they stated that the writing moved from one side to the other, or started in one place and ended in a different place. Unidirectionality was also considered identified by children if they used their finger to trace a line(s) moving in a single direction along the paper or in the air (e.g., the child states, "It goes like this," and moves finger in single direction line).

Segmentation. Segmentation was considered used if at least half of the marks were comprised of individual units with blank space surrounding them; no line from one unit could connect to another unit. A minimum of two distinct units was necessary for segmentation to be present. Segmentation was considered identified by children if they referred to spaces, marks that are by themselves, alone, separate, or used their finger to indicate each mark as its own unit (e.g., "It goes like this, this, this" pointing to each unit).

Small size. Small size of units was considered used if at least half of the marks were smaller in size relative to the marks made in the drawing example of the same referent. Small size of units was considered identified by children if they referred to the writing marks as small, little, or decreased in size compared to drawing.

Pseudo-letters. Pseudo-letters were considered used if at least one pseudo-letter was present. Pseudo-letters were considered small forms or letter-like approximations that closely resemble conventional letters; pseudo-letters were not compact scribbles. Pseudo-letters were considered identified by children if they referred to shapes that looked like letters, were makebelieve letters, or pointed to a pseudo-letter and indicated it as evidence that their writing was different from drawing.

Conventional letters. Conventional letters were considered used if at least one conventional letter was present. Conventional letters could appear slightly misshapen, rotated, or inverted, but were recognizable as a conventional letter. Conventional letters were considered identified by children if they stated 
anything about recognizing a letter, stated a letter name, stated that there were "real" letters in the writing sample, or pointed to a conventional letter and indicated it as evidence that their writing was different from drawing.

Refuse to write. The refuse to write response was indicated when, after multiple prompts, the child refused to write. It was possible for participants to refuse to write one referent but not the other. Participants who refused to write for both referents were excluded from the research question analyses.

\section{Coding Data}

The writing examples were analyzed and coded for GF-used. The number of times each graphic feature was used was recorded. Each GF-used (including refusal to write) was coded as $0=$ used in neither referent, $1=$ used in one referent but not the other, or $2=$ used in both referents. The video recordings of the meetings were analyzed and coded for GF-id. The number of times each graphic feature was identified was recorded. To account for the possibility that children might talk about graphic features that were not actually present, all GF-id were coded (whether or not they were actually present in the writing examples). Each graphic feature was coded as $0=$ =identified in neither referent, $1=$ identified in one referent but not the other, or $2=$ identified in both referents. To assure reliability of coding, a blind and independent rater analyzed half of the writing examples and video recordings and coded GF-used and GF-id (the percent agreements between raters were 96\% for GF-used and 95\% for GF-id, which were considered acceptable).

\section{Results}

\section{Preliminary Analyses and Descriptives}

Possible relationships between the demographic variables and variables of interest were explored. Due to the homogeneity of the sample, participants' gender was selected as the only demographic variable to compare with GFused and GF-id. Independent samples $t$-tests indicated no significant relationship between gender and GF-used, nor gender and GF-id.

Out of the total sample $(N=34)$, three participants refused to write for both referents (two 3-year-olds and one 4-year-old). This left $n$ $=31$ for the following descriptive statistics. Participants used a total of 210 graphic features, with an average use of $6.77(S D=3.48)$ features per participant (minimum=0; maximum=12). For GF-used, the 2-year-old group's $(n=8)$ mean was $3.63(S D=1.85)$. The 3-year-old group's $(n=12)$ mean was $6.25(S D=3.52)$. The 4-year-old group's $(n=11)$ mean was 9.63 $(S D=1.75)$.

In terms of GF-id, participants identified a total of 64 graphic features, with an average of $2.06(S D=2.46)$ graphic features per participant (minimum=0; maximum=9). The 2-year-old group identified a total of 3 graphic features ( $M$ $=0.38, S D=0.74)$. The 3-year-old group's mean was $2.17(S D=2.82)$. The 4-year-old group's mean was $3.18(S D=2.32)$.

Twenty-nine participants (93.6\%) used more graphic features than they identified. Additionally, on average, each age group used more graphic features than they identified.

The frequencies of GF-used are reported in Table 1. Linearity was the most frequent GFused for the total sample. Linearity was used a total of 45 times, comprising $21.4 \%$ of the total GF-used. Pseudo-letter was the least frequent GF-used for the total sample (22 times, 10.5\%). Linearity was the most frequent GF-used for each age group. Unidirectionality was also the most frequent GF-used for the 3 and 4-year-old groups. Pseudo-letter was the least frequent GFused among the 3 and 4-year-old group. The only GF-used with a frequency of 0 was conventional letter in the 2-year-old group.

\section{Graphic Feature Identification}

For the total sample, the most frequent GF-id included conventional letter, linearity, and unidirectionality. Conventional letter was 
Table 1

Frequency of Graphic Feature Use and Identification (ID)

\begin{tabular}{|c|c|c|c|c|c|c|c|c|}
\hline \multirow[b]{2}{*}{ Graphic Feature } & \multicolumn{2}{|c|}{$\begin{array}{l}2-y r \\
n=8\end{array}$} & \multicolumn{2}{|c|}{$\begin{array}{c}3-\mathrm{yr} \\
n=12\end{array}$} & \multicolumn{2}{|c|}{$\begin{array}{c}4-\mathrm{yr} \\
n=11\end{array}$} & \multicolumn{2}{|c|}{$\begin{array}{l}\text { Total } \\
n=31\end{array}$} \\
\hline & Use & ID & Use & ID & Use & ID & Use & ID \\
\hline Linearity & 7 & 0 & 17 & 7 & 21 & 6 & 45 & 13 \\
\hline Unidirectionality & 5 & 0 & 17 & 7 & 21 & 5 & 43 & 12 \\
\hline Segmentation & 6 & 0 & 13 & 3 & 19 & 6 & 38 & 9 \\
\hline Small size of units & 6 & 1 & 13 & 1 & 20 & 4 & 39 & 6 \\
\hline Pseudo letter & 5 & 0 & 6 & 2 & 11 & 0 & 22 & 2 \\
\hline Conventional letter & 0 & 2 & 9 & 6 & 14 & 14 & 23 & 22 \\
\hline Total & 29 & 3 & 75 & 26 & 106 & 35 & 210 & 64 \\
\hline
\end{tabular}

identified 22 times, comprising 34.4\% of the total GF-id. Linearity was identified 13 times (20.3\%). Unidirectionality was identified 12 times (18.9\%). Pseudo-letter had the lowest frequency of 2 (3.1\%).

When GF-id frequency was analyzed by age group (see Table 1), the 2-year-old group’s GFid frequency was 3 (2 were conventional letter). The 3-year-old group identified linearity and unidirectionality 7 times each, each comprising $26.9 \%$ of the total GF-id for the group. The 4year-old group identified conventional letters 14 times, comprising $40.0 \%$ of the total GF-id for the group. The 4-year-old group also identified linearity and segmentation 6 times each, each comprising $17.1 \%$ of the total GF-id for the group.

\section{Graphic Feature Identification vs. Use}

The relationship between the mean number of GF-id and the mean number of GF-used was examined. Among the sample, children used significantly more graphic features $(M=6.77$, $S D=3.48)$ than they identified $(M=2.06, S D=$ $2.46 ; t(30)=8.80, p<.05)$.

To determine if a meaningful relationship existed for each age group, one-way ANOVA was used comparing the relationship between GF-used and age. The mean number of total GFused significantly differed by age, $F(2,28)=$ $12.68, p<.05$. Post hoc comparisons using the Tukey HSD test indicated that the mean scores for the 2-year-old group $(M=3.62, S D=1.85)$ and the 3-year-old group $(M=6.25, S D=3.52)$ were significantly lower than mean score for the 4-year-old group $(M=9.64, S D=1.75)$.

Results of a one-way ANOVA comparing the relationship between GF-id and age revealed a significant relationship, $F(2,28)=3.54, p<.05$. Post hoc comparisons using the Tukey HSD test indicated that the only significant relationship was between the mean score for the 2-year-old group $(M=.38, S D=.74)$ and 4-year-old group $(M=3.18, S D=2.32)$.

\section{Discussion}

\section{Graphic Feature Use}

As expected, children in this sample used graphic features to differentiate their writing from drawing. Of the 31 participants who produced a writing example, 30 used at least one graphic feature in their writing. Within the 
sample, the most frequently used graphic feature was linearity (see Table 1). Within the 2-yearold group, linearity was most frequently used. Within the 3- and 4-year-old groups, linearity and unidirectionality were most frequently used. These results are not surprising, since linearity is a basic superordinate feature, present in all orthographies (Gibson \& Levin, 1975), and superordinate features such as linearity and unidirectionality generally appear in children's writing before the more complex ordinate features, such as conventional letters (Tolchinsky-Landsmann \& Levin, 1985). The only age group with a frequency of 0 was the 2year-old group for the conventional letter graphic feature. This is also not surprising, as children this young are just beginning to incorporate graphic features in to their writing (Treiman \& Yin, 2011; Yamagata, 2007). Figures 1 and 2 provide examples of typical drawing and writing productions by the sample, illustrating the use of linearity, unidirectionality, and other graphic features.

Based on the writing samples of these participants, linearity is a prominent feature that children include in their own writing. The frequent use of linearity is consistent with previous research. For example, Brenneman et al. (1996) reported that linearity was present in $70 \%$ of writing examples created by $4-$ to 5 year-olds. When children want to communicate that they are writing, perhaps the simplicity of linearity is relatively easy for children to translate to their own writing marks, as opposed to the more detailed and controlled features such as small size of units, pseudo letters and conventional letters. It also seems possible that children's degree of fine motor development influences which graphic features children are physically capable of producing. Children at age 2 typically have poorer fine motor control than children at age 4, influencing their writing capabilities. Perhaps features such as linearity and unidirectionality are relatively simple in terms of fine motor control.

Children's use of graphic features significantly increased between the 2- and 4year-old groups, and the 3- and 4-year-old groups. It was expected that graphic feature usage would increase with age. These findings suggest that, for these participants, graphic feature usage changes significantly between the ages of 2 and 4. Past research on children's use of graphic features indicates that many graphic features become regularly used in writing by approximately age 4 (Akita et al., 2007; Tolchinsky-Landsmann \& Levin, 1985).

It was expected that the oldest children in the sample would use the most graphic features, but it was surprising that no difference existed between the 2- and 3-year-olds. Perhaps before the age of 4 it is typical for graphic feature usage to be more sporadic, with consistent usage occurring around age 4. However, this is purely
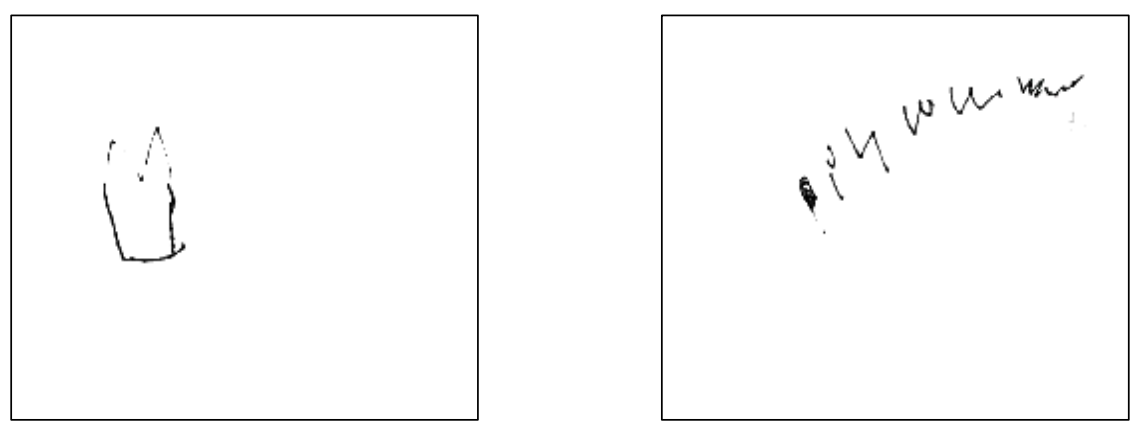

Figure 1. Example of a three-year-old participant's drawing of a house (left) and writing the word house (right). Graphic features used include linearity, segmentation, small size, pseudo-letter, and conventional letter. 

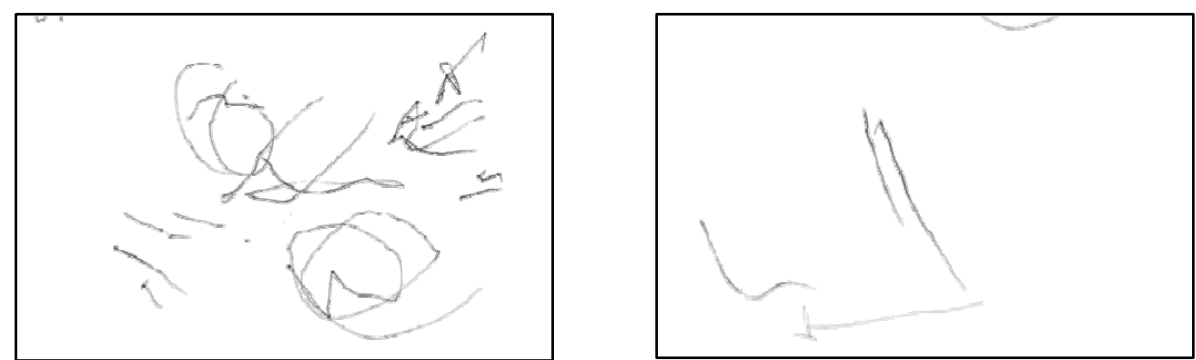

Figure 2. Example of a two-year-old participant's drawing of a flower (left) and writing the word flower (right). Graphic features used include linearity,-unidirectionality and segmentation.

speculative; it is not possible to make this conclusion from the present study. A larger study with more statistical power would be needed to more closely examine the effect of age on graphic feature usage in the youngest participants.

\section{Graphic Feature Identification}

In terms of graphic features identified, conventional letter was the most frequently identified graphic feature for the entire sample (see Table 1). One explanation for this may be that conventional letters are a more familiar concept to children than the other graphic features, and thus easier to identify in conversation. For example, previous research indicates that children demonstrate a preference for the characteristics of their language's orthography and alphabet (Treiman et al., 2007). They recognize violations in letter combinations, as well as impossible consonant-vowel combinations (Ferreiro \& Teberosky, 1982; Tolchinsky-Landsmann \& Karmiloff-Smith, 1992). Perhaps conventional letters are one of the most obvious features of writing that stand out to children. When asked why their marks looked like writing, the children in this sample made statements such as, "because I wrote letters," "I put letters on it," and "I don't know, I just did this, this, and this. This looks like A, this looks like a O.”

The 2-year-old group identified conventional letters twice despite a complete lack of conventional letters in their writing. For example, one two-year-old child stated, "you draw a H...You make a, just draw a A...F, and a C and make a F." The marks this child created were meaningful to her as letters and letters were clearly a defining characteristic in her perception of her writing. This is a very limited example because it is based on the responses of a few children, but these young children are beginning to apply the concepts of "letters" to their own writing, demonstrating their knowledge about writing as a notational system. It is worthwhile to note that children may have some implicit understanding that by identifying conventional letters, other superordinate features such as linearity and segmentation are assumed. Within the scope of this project, there is no way to dissect this issue, however, future studies could separate out and compare ordinate versus superordiante understanding.

When graphic feature identification was examined by age (see Table 1), conventional letter remained one of the most frequently identified graphic features in each age group. It is interesting that participants most frequently used the superordinate feature of linearity, but more frequently identified the orthographyspecific ordinate feature of conventional letters. Perhaps the superordinate features such as linearity are such overarching characteristics of writing systems that children use them naturally, with little conscious effort (thus making them 
hard to verbally identify). The children who did identify linearity used interesting language and gestures to communicate their understanding of this concept. For example, some children moved their finger across the marks, in a straight line while stating, "I just did this like that, that's what happened" and "I make it like this." While moving his finger along his marks, one child stated, "I did this." When the researcher asked, "What does that mean?" he stated, "Writing." While linearity was a tricky concept for the children to verbalize, linearity is easier to use than conventional letters, which take time and skill to learn. In terms of identifying features, perhaps the orthographyspecific features are more obvious to children than the superordinate features. Using conventional letters may be a more conscious effort (making them harder to use, but easier to identify). This, combined with the fact that letter names and letter sounds are commonly discussed with children (especially in early childhood classrooms), may make conventional letters easier for children to identify.

A significant relationship between graphic features used and graphic features identified was found for the sample as a whole. The participants used significantly more graphic features in their writing than they were able to identify. There are many possible explanations for this finding. Children have many opportunities to practice writing within the classroom; discussions about the graphic characteristics of writing may have been unfamiliar to the children. When the participants were asked if their writing and drawing looked different, almost every child responded "yes." When asked how they were different, children often had difficulty verbalizing an answer; however, some participants did make it clear that they knew writing marks had certain graphic characteristics. For example, children referred to their marks by stating, “....it had to do the bump thing," "It kinda looks likes mountains," and "I would just write like up and down." Other children referred to the size of the marks by stating, "this one is big and this one is small," and "I kinda just scribbled...going up and down.” While graphic feature usage was significantly higher than graphic feature identification, the participants in this sample were capable of communicating their ideas about the graphic characteristics of writing.

The literature makes clear that children are visually aware of different graphic features (Clay, 1975; Harste et al., 1984; Levin \& Bus, 2003; Tolchinsky-Landsmann \& KarmiloffSmith, 1992; Treiman et al., 2007); participants in this sample may have noticed the differences between their writing and drawing marks, they were just unable to verbalize their thoughts about the graphic features. However, some participants made interesting observations about the differences between their writing and drawing, despite identifying very few graphic features. For example, one 4-year-old participant stated, "Because they aren't the same because you draw a flower and then draw the word because flowers aren't the same as words." When the researcher asked, "Why aren't flowers the same as words?" the child stated, "Because the words are M's and Y's and all sorts of stuff and the flower is just a thing. The flower is what you send to talk with." Statements such as this reflect a real understanding of why writing is different than drawing. It would be interesting to see if children's thoughts about writing would change or be enhanced with experience discussing writing at the graphic level. Using language to discuss many different graphic features of writing may influence the way children perceive the strategies they use in their own writing.

A significant increase in graphic feature identification was found between the 2- and 4year-old groups only. It may be very likely that this is due to verbal ability. The current study showed no significant increase between the 2and 3-year-old group and the 3- and 4-year-old group. As discussed previously, perhaps there is a large increase in recognizing graphic features that occurs around age 4. Again, this is purely speculative; a larger study with more statistical power would be needed to clarify this idea. For the present study, making comparisons between the age groups is limited; 
meaningful differences for graphic feature identification between age groups may be found in a larger sample. Alternatively, the differences between age groups may be simply related to verbal ability.

\section{Limitations}

This study is limited in its generalizability. This study examined a small portion of the population of children and families involved in child care at a university campus; in terms of marital status, ethnicity, family education, and household income, the population showed very little variability. This study should be considered as a starting point to this topic; utilizing a larger, more diverse population would help identify demographic characteristics that are related to this topic. Six children reported speaking a language other than English at home; this issue was not addressed in this study (all six children were proficient in English), but has the potential to be in influencing variable. Future studies with larger, more diverse samples may want to separately examine mono- and multilingual children.

Another limitation of the present study was small sample size. Comparing results across age groups would be more accurate if this study was replicated with more statistical power. This would provide clearer trends in which graphic features children most frequently use and identify in their own emergent writing. A larger sample would help identify changes that occur in graphic feature use and identification across age groups, and may reveal more statistically significant differences between the age groups than was possible for the current project. Participation was also voluntary, thus, some children and families from the target population did not participate. Despite parental consent, some participants refused to assent to participate as well. There may be characteristics about those families and children who consented and assented to participate that are unique, reducing the generalizability of this project.

The children sampled for this study attended child care at a university campus. The center's philosophy and curriculum included a strong incorporation of literacy within the environment, access to numerous literacy materials, and facilitation of emergent writing. This campus child care program was also nationally accredited; accredited child care centers are regulated by higher standards of quality and developmentally appropriate practices than nonaccredited child care centers. The qualities and experiences provided by this campus child care center may have influenced or enhanced the sample's graphic feature usage and identification. Future research on this topic should included different populations, such as children from community child care programs and children who do not attend child care. The context of any child care classroom also varies greatly from the context of the home. Studies that examine the effect of the home and child care context (campus or community; accredited or non-accredited) on knowledge about one's own emergent writing should be included in the future research on this topic.

\section{Applications to Early Childhood Education and Future Research}

The classroom is a powerful contextual influence on children's development and internalization of writing (Dyson, 2008; Love et al., 2007; NICHD, 1998). It is important to consider how the findings of this study can be practically applied to early childhood classrooms. Early childhood educators have ample opportunities to engage children in discussions about their writing and drawing. Young children engage in meaningful writing experiences and understand that their writing differs from their drawing (Adi-Japha et al., 1998; Clay, 1975; Harste et al., 1984; Levin \& Bus, 2003; Sulzby et al., 1989; Treiman \& Yin, 2011; Yamagata, 2007). The finding of this study suggest that children are able to discuss the features of their writing, as well as discuss the features they perceive to be important, even if they cannot produce conventional examples. Early childhood teachers should be sensitive to this, and openly ask children about their 
knowledge of writing as a notational system. This may provide teachers with greater insight to their students' thought processes during writing.

This is not to suggest that children need direct instructional lessons in this area; however, teachers may find it useful to comment on the graphic features children use (e.g., "I see you put the letters in a line.”) or ask children what strategies they used to create their writing. If young children are more consciously aware of the graphic strategies they use, perhaps this could enhance their ability to communicate to others through their writing.

The participants in this study were capable of examining their writing at the graphic level and shared some valuable insights to their ideas about what makes writing different from drawing. Future research may want to examine how this can be utilized in early childhood classrooms to enhance children's understanding of the process they engage in while writing. Teachers can facilitate conversations about the graphic aspects of writing to help children gain more insight about writing as its own system and domain of knowledge. Conventional letters are commonly discussed, but perhaps it would be beneficial to discuss the other features as well. Bringing the other features to a more conscious level through language may provide children with a different view of the intentions and meaning behind their own writing. Making some of the implicit features of writing explicit could be explored as a possible teaching tool for young students.

Future research in this area may want to examine how graphic feature usage and identification fits in with larger developmental models of emergent writing. Levin and Bus (2003) developed an emergent writing scale that consisted of three schemes: graphic, writing-like, and symbolic. Early scribbles and small forms made up the graphic scheme; the majority of graphic features that were the focus of the current project were included within the writinglike scheme.

More complex developments such as phonetic representation and invented spelling comprised the symbolic scheme. It may be beneficial to examine how graphic feature identification fits with these types of models, and how these types of models fit with models of emergent writing that extend to elementary school-aged children. If young children were capable of examining writing at the graphic level, perhaps including their conversations would enhance models that solely examine their actual writing productions. Mastering many of the graphic characteristics of writing is necessary before writing can be used to communicate successfully to others; children's understanding of this process may be an important piece to consider when examining emergent writing.

\section{Conclusion}

The purpose of this project was to examine children's understanding of the graphic features they use to differentiate their emergent writing from drawing. Examining this topic in terms of what children can express through conversation provided a different way of viewing children's perceptions of their own emergent writing. This project explored which features of writing children can express and highlighted potential relationships between the features children can express and the features they use. The findings from this project will hopefully help generate new ideas for larger, more comprehensive studies.

Acknowledgements: This study is based on a thesis from the University of Nevada, Reno. The authors would like to thank committee members Dr. Eva Essa and Dr. Julie Pennington for their assistance and support throughout this project.

\section{References}

Adi-Japha, E., Levin, I., \& Solomon, S. (1998). Emergence of representation in drawing: The 
relation between kinematic and referential aspects. Cognitive Development, 13, 25-51.

Akita, K., Padakannaya, P., Prathibha, B., Panah, M. A., \& Rao, C. (2007). Drawing and emergent writing in young children. National Academy of Psychology, India, 52, 216-222.

Brenneman, K., Massey, C., Machado, S. F., \& Gelman, R. (1996). Young children's plans differ for writing and drawing. Cognitive Development, 11, 397-419.

Clay, M. (1975). What did I write? Auckland, New Zealand: Heinemann Educational Books.

Dyson, A. H. (2008). Staying in the (curricular) lines: Practice constraints and possibilities in childhood writing. Written Communication, 25, 119-159.

Ferreiro, E., \& Teberosky, A. (1982). Literacy before schooling. Portsmouth, NH: Heinemann.

Gibson, E. J., \& Levin, H. (1975). The psychology of reading. Cambridge, MA: MIT Press.

Gombert, J. E., \& Fayol, M. (1992). Writing in preliterate children. Learning and Instruction, 2, 23-41.

Harste, J. C., Woodward, V. A., \& Burke, C. L. (1984). Language stories and literacy lessons. Portsmouth, NH: Heinemann Educational Books.

Hildreth, G. (1936). Developmental sequences in name writing. Child Development, 7, 291303.

Karmiloff-Smith, A. (1992). Beyond modularity: A developmental perspective on cognitive science. Cambridge, MA: The MIT Press.

Lavine, L. O. (1977). Differentiation of letterlike forms in prereading children. Developmental Psychology, 13, 89-94.

Levin, I., \& Bus, A. G. (2003). How is emergent writing based on drawing? Analyses of children's products and their sorting by children and mothers. Developmental Psychology, 39, 891-905.

Levin, I., \& Korat, O. (1993). Sensitivity to phonological, morphological and semantic cues in early reading and writing in Hebrew. Merrill-Palmer Quarterly, 39, 213-232.
Love, A., Burns, S. M., \& Buell, M. J. (2007). Writing: Empowering literacy. Young Children, 62, 12-19.

Luria, A. R. (1929). The development of writing in the child. Problems of Marxist Education Volume 1 (pp. 143-176). Moscow: Academy of Communist Education.

NICHD Early Child Care Research Network. (1998). The NICHD study of early child care (Report No. NIH-Pub-98-4318). Bethesda, MD: National Institute of Child Health and Human Development. (ERIC Document Reproduction Service No. ED427882)

Pick, A. D., Unze, M. G., Brownell, C. A., Drozdal, J. G., \& Hopmann, M. R. (1978). Young children's knowledge of word structure. Child Development, 49, 669-680.

Sulzby, E., Barnhart, J., \& Hieshima, J. (1989). Forms of writing and rereading from writing: A preliminary report. In J. Mason (Ed.), Reading and writing connection (pp. 31-63). Needham Heights, MA: Allyn \& Bacon.

Tolchinsky, L. (2003). The cradle of culture: Knowing about writing and numbers before being taught. Mahwah, NJ: Lawrence Erlbaum.

Tolchinsky-Landsmann, L., \& Karmiloff-Smith, A. (1992). Children's understanding of notations as domains of knowledge versus referential-communicative tools. Cognitive Development, 7, 287-300.

Tolchinksy-Landsmann, L., \& Levin, I. (1985). Writing in preschoolers: An age-related analysis. Applied Psycholinguistics, 6, 319339.

Treiman, R., Cohen, J., Mulqueeny, K., Kessler, B., \& Schechtman, S. (2007). Young children's knowledge about printed names. Child Development, 78, 1458-1471.

Treiman, R., \& Yin, L. (2011). Early differentiation between drawing and writing in Chinese children. Journal of Experimental Child Psychology, 108, 786-801.

U.S. Census Bureau. (2005). Who's minding the kids? Child care arrangements: Spring 2005 detailed tables. Washington D.C.: U.S. Census Bureau. 
Vygotsky, L. S. (1978). Mind in society. Cambridge, MA: Harvard University Press.

Whitehurst, G. J., \& Lonigan, C. J. (1998). Child development and emergent literacy. Child Development, 69, 848-872.

Yamagata, K. (2007). Differential emergence of representational systems: Drawings, letters, and numerals. Cognitive Development, 22, 244-257.
Received October 8, 2011

Revision Received December 29, 2011

Accepted January 27, 2012 